\title{
PSICANÁLISE, LITERATURA E EDUCAÇÃO: UMA ESCRITA PARA A DESPATOLOGIZAÇÃO DO SINTOMA DISORTOGRÁFICO
}

\author{
Andréa Hortélio Fernandes (UFBA)* \\ https:orcid.org/0000-0002-3730-2198 \\ Claudia Maria Tavares Saldanha (UFBA)** \\ https:orcid.org/0000-0002-3470-4829
}

\section{RESUMO}

0 artigo parte da premissa de que a contínua interlocução entre a psicanálise e a literatura teria contribuído para a despatologização do conceito de sintoma na teoria psicanalítica. Os questionamentos examinados no texto são: Em que medida esse intercâmbio entre a literatura e a psicanálise pode ter ressonâncias nas pesquisas com fundamentação da psicanálise e que se relacionam com outros campos de saber, como, por exemplo, a educação? Um percurso pela interlocução entre os dois campos poderia fornecer subsídios para uma despatologização do sintoma em tempos de crescente ampliação e utilização de diagnóstico na educação, em especial em torno dos transtornos de aprendizagem tais como o sintoma disortográfico? Através de um recorte clínico, examina e defende algumas contribuições da teoria da clínica psicanalítica que podem auxiliar no manejo dos impasses com o saber durante a alfabetização que circunscreve, também, o momento lógico de efetuação da estrutura psíquica da criança.

Palavras-Chave: Psicanálise. Literatura. Educação. Sintoma disortográfico.

\section{ABSTRACT \\ PSYCHOANALYSIS, LITERATURE AND EDUCATION: A WRITING FOR DEPATOLOGIZING THE SYMPTOM DISORTOGRAPHIC}

The article starts from the premise that the continuous dialogue between psychoanalysis and literature has contributed to the depatologization of the concept of the symptom in psychoanalytic theory. The questions that are examined in the text are: How far can this exchange between literature and psychoanalysis have resonances in investigations based on psychoanalysis and

\footnotetext{
* Doutora em Psicopatologia Fundamental e Psicanálise (Paris VII). Professora da Graduação e Pós-Graduação em Psicologia da Universidade Federal da Bahia (UFBA). Membro do GT Psicanálise, Política e Clínica da Associação Nacional de Pesquisa e Pós-Graduação em Psicologia (ANPEPP). Analista Membro da Escola de Psicanálise dos Fóruns do Campo Lacaniano (EPFCL-Brasil). Membro do Fórum do Campo Lacaniano Salvador. E-mail: ahfernandes03@gmail.com

** Mestra em Psicologia pela Universidade Federal da Bahia (UFBA). Membro da Internacional dos Fóruns do Campo Lacaniano (IF/EPFCL-Brasil) e do Fórum do Campo Lacaniano Salvador. E-mail: cmtsaldanha@gmail.com
} 
related to other fields of knowledge, such as education? Could a path through the dialogue between psychoanalysis and literature support a depatologization of the symptom in times of growing expansion and the use of diagnosis in education, especially around learning disorders such as disortographic symptoms? Through a clinical approach, it examines and defends some contributions from the theory of the psychoanalytic clinic that can help in the management of the callejones without knowing during the literacy, which also circumscribe the logical moment to affect the psychic structure of the child.

Keywords: Psychoanalysis. Literature. Education. Disortographic symptom.

\section{RESUMEN \\ PSICOANÁLISIS, LITERATURA Y EDUCACIÓN: UN ESCRITO PARA DESPATOLOGIZAR EL SÍNTOMA DISORTOGRÁFICO}

El artículo parte de la premisa de que el diálogo continuo entre psicoanálisis y literatura ha contribuido a la despatologización del concepto de síntoma en la teoría psicoanalítica. Las preguntas que se examinan en el texto son: ¿Hasta qué punto este intercambio entre literatura y psicoanálisis puede tener resonancias en investigaciones basadas en el psicoanálisis y relacionadas con otros campos del conocimiento, como la educación? ¿Puede un camino a través del diálogo entre psicoanálisis y literatura sustentar una despatologización del síntoma en tiempos de expansión creciente y el uso del diagnóstico en la educación, especialmente en torno a trastornos del aprendizaje como los síntomas disortográficos? Mediante un abordaje clínico, examina y defiende algunos aportes de la teoría de la clínica psicoanalítica que pueden ayudar en el manejo de los callejones sin saber durante la alfabetización, que también circunscriben el momento lógico para afectar la estructura psíquica del niño.

Palabras clave: Psicoanálisis. Literatura. Educación. Síntoma disortográfico.

\section{Uma interlocução entre a psicanálise, a literatura e 0 sintoma disortográfico da criança}

A aproximação entre a psicanálise e a literatura possibilitou que a noção de sintoma ganhasse uma nova acepção. Tal fato repercute diretamente na clínica, uma vez que o sujeito histoeriza ${ }^{1}$ aquilo que lhe causa mal-estar por meio de recursos da linguagem encontrados também na literatura e na poesia, em especial metáforas e metonímias. 0 conceito de alíngua, proposto por Lacan (1985), é fundamental

1 Referência ao neologismo histoeria [hystoire] que reúne as palavras "história” e "histeria” (LACAN, 2003e, p. 567). para pensar a interpretação, operando a partir do equívoco linguageiro, o que aproxima os "truques linguísticos" (FREUD, 2006a, p. 329) próprios à literatura e à poesia do tratamento analítico de dificuldades da criança com o aprendizado da leitura e da escrita em meio à alfabetização.

0 presente artigo pretende sustentar a hipótese de que tanto a literatura como a psicanálise vão convocar seja o escritor criativo, seja a criança com sintoma disortográfico a se servirem dos significantes para daí poderem saber-fazer com sua realidade psíquica. Tal fato tem como disparador um ponto de extimidade do saber que é alíngua, visto que é por uma elucubração de saber, em ambos os casos, que isso acontece. 
No tratamento psicanalítico pela associação livre, sob transferência, a criança lida com a alíngua naquilo que ela conjuga significante e gozo. No caso do escritor, é no ato da escrita que uma obra nasce. Ela parte, então, de algo que lhe é extimo e, ao mesmo tempo, é um produto das argumentações, pensamentos e que na própria construção se elaboram e reelaboram. A noção de extimidade é importante para refletir acerca da acepção do sintoma para a psicanálise. 0 sujeito não é seu sintoma, mas o sintoma é uma forma de o sujeito se expressar, é uma das manifestações do inconsciente.

Diante disso, quais as possíveis ressonâncias dessa interface entre a psicanálise e a literatura nas pesquisas com fundamentação psicanalítica que se relacionam com outros campos de saber, como, por exemplo, a educação?

Entre a psicanálise e a literatura formalizase uma relação na qual uma caminha pari passu à outra no que tange a estar à altura do exame da subjetividade da época. Muitas vezes, os psicanalistas reconheceram que a literatura deu tratamento aos processos psíquicos e a temas pungentes da existência humana antes mesmo que a psicanálise tivesse a eles se dedicado.

A literatura fez parte do interesse de Freud desde os tempos da juventude prévios ao ingresso no curso de medicina. É sabido que ele manteve uma intensa troca epistolar com colegas dos mais variados campos de saber, como médicos, religiosos, escritores e analistas em formação com ele. Nessa comunicação, Freud (ZWEIG; FREUD, 1991, p. 114, tradução nossa) escreveu uma carta ao escritor Stefan Zweig na qual destacou o papel da pesquisa de relançar e de atualizar questões acerca do laço entre a psicanálise e a subjetividade em diferentes épocas: "Meu trabalho fica como legado, como o senhor disse. Ninguém pode predizer como as gerações futuras o avaliarão. Eu mesmo não estou muito seguro, de todo modo a dúvida é inseparável da pesquisa, e nós só encontramos uma pequena parcela da verdade."

A psicanálise nasce da medicina, porém a extrapola e cria uma abordagem terapêutica própria que, continuamente, recorre à literatura para abordar e manejar o sofrimento humano. Sofrimento humano deve ser tomado no sentido mais amplo do termo, podendo envolver uma grande variedade de queixas que estão en souffrance, expressão que, em francês, denota algo que está em espera. Nesse contexto específico, na espera de uma escuta que possa dar um encaminhamento clínico.

Com o passar dos anos, várias edições dos manuais de classificação dos transtornos mentais são editadas, e, cada vez mais, a escuta clínica do sujeito em sofrimento é posta em segundo plano à catalogação dos sintomas tomados como transtornos a serem corrigidos por via, sobretudo, da farmacoterapia. A grande aderência ao consumo de medicamentos e a não escuta do sujeito convocam a retomada da evolução da noção de sintoma pela psicanálise como aposta de um possível refreamento da psicopatologização da vida cotidiana.

No que tange ao campo da educação, a busca incessante da excelência em resultados pedagógicos pode deixar de lado o singular de cada caso e, com isso, reduzir as dificuldades de aprendizagem da leitura e da escrita, que podem advir no momento da alfabetização, aos diagnósticos dos manuais de classificação dos transtornos mentais.

0 transtorno de aprendizagem é comumente tratado com os termos dislexia, disortografia e discalculia, sendo, respectivamente, o transtorno da leitura, o transtorno da escrita e o transtorno da matemática (FERNÁNDEZ et al., 2010; LIMA; PESSOA, 2007; MUÑOZ et al., 2015; SAMPAIO, 2011; VALERIANO, 2011). Cabe então examinar em que medida a interlocução com a literatura e com a poesia, com truques e equívocos linguísticos tão frequentes, podem auxiliar o tratamento psicanalítico do sintoma disortográfico.

Soler (2012a, p. 51) elabora que "a disortografia é um sintoma em suma especial", pois o sintoma do sujeito, enquanto uma manifestação subjetiva, é "disortográfico" por definição, pelo fato de o inconsciente não obedecer às normas 
gramaticais e ortográficas e por ser regido por uma sintaxe singular e escrita com as letras de alíngua. Assim, o sintoma é disortográfico, pois o "inconsciente-alíngua" (SOLER, 2012a, p. 40) é estruturado disortograficamente.

Ao recorrer à etimologia da palavra disortografia, a presença do prefixo de origem grega "dis" denota uma dificuldade (CUNHA; CINTRA, 2007), o que caracteriza o termo como uma patologia. Logo, para as ciências que se embasam em um discurso pedagógico hegemônico e biologicista, a disortografia, termo aplicado em sua forma substantiva, é um nome para o transtorno de aprendizagem que envolve a escrita, o que representa que o sujeito se encontra em dificuldade com a aprendizagem da ortografia.

Com a psicanálise, a disortografia assume o estatuto de adjetivo por caracterizar o sintoma do sujeito como disortográfico, uma leitura que coloca em suspenso a marca de dificuldade presente na palavra. Desse modo, o campo psicanalítico se apropria dessa nomenclatura de uso comum pelas ciências que se dedicam ao tratamento das dificuldades e transtornos de aprendizagem e a subverte com o intuito de revelar as especificidades que regem o inconsciente e o sintoma.

\section{0 sintoma na psicanálise e os truques linguísticos da literatura e da poesia}

A publicação de $A$ interpretação dos sonhos por Freud (1972a) é tida como o marco inaugural da psicanálise propriamente dita. 0 inconsciente, já explorado por outros campos do saber, é interpretado por meio de elementos novos, ao passo que o sonho é lido como a via régia, além do chiste, do ato falho e do sintoma, como afirma Fernandes (2012). Os meios à disposição dos sonhos para manifestar os conteúdos inconscientes são sistematicamente aproximados por Freud (1972b) não só da poesia como também da fantasia. Para ele, os sonhos criam estruturas compostas que, reiteradamente, emprestam uma aparência fantástica similar às fantasias, aos devaneios e aos delírios.

Nos sonhos, segundo Freud (1972b), é comum encontrar uma técnica mais elaborada que combina os traços de alguns objetos com uma nova imagem e, ao proceder assim, utiliza, com habilidade, semelhanças que os dois objetos possuem na realidade. A nova estrutura composta pode parecer inteiramente absurda ou provocar a impressão de um sucesso imaginativo que faz, tantas vezes, o sonhador afirmar que teve um sonho estranho. Nisso, a deformação presente na formação dos sonhos se assemelha bastante às fantasias produzidas por sujeitos e a alguns textos de escritores.

Freud, ao longo de sua obra, mostra como os sonhos, os chistes e os atos falhos guardam uma aproximação especial com a poesia por também fazerem uso de truques linguísticos. 0 mesmo se produz com o esquecimento de nomes próprios. Acerca disso, cita o exemplo envolvendo o nome do pintor Signorelli para mostrar que o motivo atuante no recalcamento está presente também no esquecimento do nome do pintor (FREUD, 1972c). Logo, o sintoma, como outras manifestações do inconsciente, ou melhor, formações do inconsciente, como propõe Lacan (1999), tende a fazer uso de certa poesia para fazer passar o que do inconsciente insiste e resiste à interpretação.

Freud (1972e) aponta a necessidade de uma verdadeira ars poética para que o sintoma possa extrapolar a dimensão de satisfação egóica que ata o sujeito a um mal-estar. Novamente, faz uma aproximação com a literatura, no caso, com o escritor criativo, visto que o sujeito com sintoma lida com o mal-estar a ele associado através de deformações e disfarces linguísticos utilizados também pelos escritores. A partir dessa descrição feita por Freud, podemos dizer que o sintoma do sujeito representa o modo como ele lida, goza com o inconsciente na medida em que o inconsciente o determina. Temos aí a definição de sintoma proposta por Lacan (2020a), no Seminário R.S.I., que 
deve ser trabalhada, concomitantemente, à definição do inconsciente estruturado como uma linguagem, a qual foi formulada quando realizou o retorno aos fundamentos freudianos (LACAN, 1998c).

A psicanálise, desde sempre, constitui-se como um tratamento pela fala. Nos primórdios das suas elaborações, Freud costumava dar um tom romanceado à escrita dos seus casos clínicos. É possível aproximar tal fato da própria concepção do sintoma enquanto retorno do recalcado que se repete e apresenta um tom romanesco.

O romance, concebido como uma composição poética popular, durante o período medieval, era transmitido pela tradição oral. Na idade moderna, o romance é um gênero narrativo no qual, ao final, há um enfraquecimento na combinação e na ligação de elementos heterogêneos. Nisso, é possível aproximá-lo à descrição do tratamento psicanalítico produzida por Freud (1972f), segundo a qual trata-se de fazer da miséria neurótica um sofrimento banal.

No início, é preciso trabalhar a demanda para tornar o sofrimento do sujeito uma questão ligada à sua existência, ou seja, à forma como um ser falante constrói sua realidade psíquica a partir daquilo que na sua história lhe é singular. No que tange à clínica psicanalítica com a criança, a histoerização se dá, também, por meio da fala, além das produções lúdicas como desenhos e jogos. Se o psicanalista deve aprender a lição lá onde o artista lhe abre o caminho, é possível dizer que a psicanálise toma por direção o tratamento pela fala para objetivar o real, cuja elaboração se formaliza pela conceitualização em torno das noções de letra e de alíngua (LACAN, 1985).

\section{A alíngua e os impasses da criança frente ao saber em meio à alfabetização}

O conceito de alíngua foi criado por Lacan (1985) para situar que a linguagem, de início, não existe, pois ela é o que se tenta elucubrar concernente à função de alíngua. Isso testemunha a existência de um saber inconsciente que escapa ao ser falante e que está para além da língua ortográfica por dizer respeito ao real e ao gozo, o qual estrutura e se manifesta no sintoma (SOLER, 2012a).

O saber inconsciente é não todo, pois a divisão subjetiva inerente ao falasser impõe uma falta que o impossibilita de estar articulado a uma verdade absoluta. Assim, o saber no humano se constitui para além do determinismo biológico, uma vez que é dada a possibilidade de fazer escolhas pela forma como subjetiva a realidade.

Por sua vez, o saber escolar se estrutura em um idealismo do saber absoluto a ser transmitido às crianças, por meio do discurso pedagógico hegemônico, com a função de frear as pulsões ainda desorganizadas e de cifrá-las para se adequarem às normas do sistema educacional (NOMINÉ, 2002; RESTREPO, 2014). Apesar dessa diferenciação, para que a criança possa acessar o conhecimento inerente à alfabetização, ela precisa advir como sujeito intérprete do saber inconsciente escrito no texto da própria história, marco determinante para a efetuação da estrutura.

A dificuldade de aprendizagem da criança que adentra a escolarização formal com o intuito de aprender a ler e a escrever é um tema recorrente no campo da educação (MELO, 2016). Essa questão tem produzido mobilizações em nível mundial para que seja alcançado o êxito na chamada "alfabetização universal" (ORGANIZAÇÃO DAS NAÇÕES UNIDAS PARA A EDUCAÇÃO, A CIÊNCIA E A CULTURA, 2014, p. 10), a qual é concebida como fundamental para o avanço social e econômico. As metas e as estratégias adotadas para que essa demanda seja sanada se direcionam à promoção de uma educação de qualidade que possa viabilizar a participação escolar e a consequente alfabetização universal "como caminho para uma aprendizagem relevante e efetiva" (ORGANIZAÇÃO DAS NAÇÕES UNIDAS PARA A EDUCAÇÃO, 
A CIÊNCIA E A CULTURA, 2016, p. 38). Frente a isso, nota-se a universalização da alfabetização e a redução desse processo a uma problemática que engloba somente os campos da educação, da política e da economia, excluindo a participação da subjetividade na relação que a criança estabelece com o saber ao se alfabetizar, a qual pode trazer impasses para a aprendizagem da leitura e da escrita.

A psicanálise propõe pensar a alfabetização como o início da circulação da criança no "discurso alfabético" (DUNKER, 2011, p. 1), um processo singular que corresponde a uma nova conjuntura subjetiva que implica em rearranjos pulsionais atrelados à lógica da efetuação da estrutura, o que nem sempre coincide ao tempo determinado pelo discurso pedagógico hegemônico que orienta o alfabetizar e que demanda o êxito escolar. Desse modo, a questão da relação da criança com o saber se mostra relevante nessa discussão, visto que o discurso analítico apresenta uma distinção entre o saber inconsciente e o saber escolar, entre saber e conhecer.

Trata-se, então, de um trilhamento que institui a alfabetização como uma alfabestização (LACAN, 2008), neologismo que articula a estruturação subjetiva e a entrada no discurso alfabético à leitura do saber não todo escrito pelo significante besta, ou seja, significante sem sentido de alíngua. Isso porque, de início, o significante de alíngua fica indeciso entre um fonema, um ruído, visto que a criança está num ambiente de linguagem, mas não a domina ainda (LACAN, 1985).

Desse modo, com Lacan (1998c), o erro ortográfico da criança que está a aprender a leitura e a escrita não é interpretado como uma significação falha, mas como um equívoco que revela a singularidade do inconsciente-alíngua, o que aponta para um tempo lógico de estruturação subjetiva, no qual a criança brinca com letras e com palavras para construir teorias sobre as marcas do dizer do Outro, que tem naqueles que exercem as funções parentais seus representantes.

\section{A patologização e a medicalização dos impasses da criança com a leitura e com a escrita}

Na contemporaneidade, a criança vem sendo posicionada pelo discurso científico como objeto de múltiplas e diversas investigações, teorizações e práticas. Ao passo que a produção de um saber sobre a criança proporcionou melhorias nos âmbitos social, político e jurídico, verifica-se o surgimento de um discurso biologicista, patologizante e segregador sobre a infância, o qual incentiva a medicalização das questões escolares (CIRINO, 2001; MELO, 2016; PACHECO, 2012). 0 que se observa é que esse discurso perpassa os ideais familiares, o processo de escolarização e o tratamento dado ao sintoma da criança, constituindo-se como um saber idealizado e universalizado que pretende descrever, nomear e categorizar. Isso tem gerado a proliferação de crianças diagnosticadas com dificuldades e transtornos de aprendizagem, entre outras nomenclaturas, pelo fato de serem interpretadas como anormais e desviantes de normas pré-concebidas por manuais classificatórios (BAUTHENEY, 2011; EDINGTON, 2012; FERNANDES, 2013; FERREIRA, T., 2000).

0 ato diagnóstico adquire a função de suturar os pontos de enigma e de não saber ao tentar validar e justificar o real que se presentifica nos atos, falas e condutas da criança, a qual, com isso, é objetalizada e desimplicada do seu sintoma (FERREIRA, T., 2008). 0 sintoma, então, é instituído como transtorno a ser eliminado, o que conduz à afirmação de que, na contemporaneidade, o sofrimento e a loucura da criança se encontram "sob o manto dos transtornos" (FERREIRA, T., 2008, p. 2).

A patologização e a medicalização dos impasses no processo de aquisição da leitura e da escrita se mostram naturalizadas não apenas para a área médica, como também para uma série de outros profissionais que se dedicam às dificuldades do não aprender, como psicólogos, neuropsicólogos, psicopedagogos e fonoaudió- 
logos. É possível, então, analisar que, diante das intervenções massificantes e uniformizantes, surgem os casos de crianças que desafiam o saber todo que orienta esses especialistas e que insistem em se fazer escutar. Trata-se da "objeção do sujeito ao estabelecido, ao gozo para todos, que é a reivindicação de uma singularidade que torna a criança rebelde, por natureza" (RESTREPO, 2014, p. 401). São, então, etiquetadas como crianças que não aprendem e que fracassam e que, por conta disso, são encaminhadas para diversos tratamentos a fim de serem reeducadas e reintegradas ao sistema escolar (COUTO, 2003). Pelo fato de a criança estar em um momento decisivo da efetuação da estrutura, essa lógica discursiva pode gerar implicações para a sua estruturação subjetiva.

A psicanálise interpreta que a objetalização da criança e a patologização do sintoma disortográfico são efeitos do discurso universitário que "faz proliferar doenças e doentes. Doenças sem marcadores biológicos evidentes, segregadoras, que foracluem o sujeito, seu desejo, sua fala" (MELO, 2016, p. 262). Como adverte Sauret (1998, p. 30), "não se trata de negar a existência de determinantes como o organismo, a sociedade, a história", mas de responsabilizar o sujeito pelo o que ele faz com esses determinantes, o que se mostra como uma subversão da psicanálise perante outras lógicas discursivas que tomam a infância como objeto de investigação. Assim, com a psicanálise, a criança pode encontrar "um meio eficaz para lutar contra os efeitos nefastos do discurso que domina o campo social contemporâneo, esse misto de capitalismo e de ciência" (SAURET, 1998, p. 44).

\section{0 caso Lia: as letras do inconsciente-alíngua e 0 tratamento dado ao sintoma disortográfico pelo discurso do analista}

Em uma pesquisa de mestrado (SALDANHA, 2017) realizada por meio do método de cons- trução do caso clínico de uma criança nomeada como Lia, nome fictício escolhido por corresponder ao verbo ler no pretérito imperfeito do indicativo, foram examinados os impasses com a leitura de algumas letras. Cabe ressaltar a homofonia entre as pronúncias do verbo "ler" e da letra "lê", a letra "éle" como era enunciada por Lia, a qual permeava todos os nomes próprios da família da menina.

A construção do caso clínico trabalhou em torno das marcas das letras de alíngua que escrevem o texto do sujeito e que se manifestam no sintoma disortográfico, revelando a participação do saber inconsciente na formação desse sintoma. Para tanto, o termo "disortográfico" foi circunscrito para caracterizar o sintoma da criança que se encontra em impasse com o saber em um momento lógico de efetuação da estrutura e de entrada no discurso alfabético. Lia estava na alfabetização, sofria as exigências da mãe para ler e escrever e encontrava dificuldades com o saber escolar, pois se deparava com as convocações do saber inconsciente, o qual lhe demandava um tempo singular para ser elaborado e interpretado.

O sintoma disortográfico, como todo sintoma para a psicanálise, aponta para um modo de gozar ao localizar o gozo perverso polimorfo que perdura na estrutura do falasser como uma escrita, uma letra de gozo (SOLER, 2012a, 2012b). 0 conceito de disposição perverso polimorfa, proposto por Freud (1972d), enoda o sexual ao pulsional e o aproxima do inconsciente e do infantil, elaboração que permite defender a ideia de que a sexualidade preserva o infantil. Dito de outro modo, a premissa freudiana de que a polimorfia pulsional das experiências sexuais da criança persiste na vida sexual do dito adulto enuncia que "a psicanálise foi obrigada a atribuir a origem da vida mental dos adultos à vida das crianças e levar à sério o velho ditado que diz que a criança é o pai do homem" (FREUD, 1972g, p. 218). Essa citação é uma referência ao poema The Rainbow, ${ }^{2}$ de

2 “O Arco-Íris. Meu coração saltou quando eu vi um arco-íris no céu: Assim foi quando minha vida começou; Assim é 
William Wordsworth (2017), um notável enlace entre psicanálise e poesia.

Na relação com o Outro, representado pelos semelhantes que lançam o infans num banho de linguagem, o acento é colocado na alíngua ouvida que carrega os rastros do gozo desse Outro. À maneira de falar do Outro se acrescenta a contingência do ouvir da criança que capta esses traços de gozo, o que traz à tona a questão da participação da criança em sua estruturação subjetiva (SOLER, 2012a). Lacan (1985), então, articula a água da linguagem que escreve os traços de gozo com as letras de alíngua ao trabalho de erosão das águas que escoam e ravinam a terra, produzindo a escrita do relevo, cuja definição é dada pelo neologismo lituraterra (LACAN, 2003b), o qual equivoca com literatura.

Devido à "sua constância e sua fixidez a um só tempo gozosa e incômoda, [...] o sintoma ancora, fixa, faz fixão" (SOLER, 2012a, p. 147) de um elemento qualquer do inconsciente tornado letra gozada. 0 sintoma é uma cifra de gozo e, "por ser escrito em letras de inconsciente-alín$g u a$, é sempre ele próprio analfabeto, ignorante da escrita ortográfica. É escrito sem ortografia e sem sintaxe. [...] Logo, sempre disortográfico o sintoma, por definição" (SOLER, 2012a, p. 51). Assim, tal qual o sonho, o ato falho e o chiste, o sintoma disortográfico se utiliza de truques linguísticos que são explorados na literatura e na poesia. Reitera-se que, em razão de o sintoma ser "puramente o que alíngua condiciona" (LACAN, 2007, p. 163), ele não é todo decifrável, e os pedaços lidos, suas letras, permanecem hipotéticas. Diante disso, "se o sintoma pode ser lido, é por já estar inscrito, ele mesmo, num processo de escrita" (LACAN, 1998b, p. 446), o qual corresponde ao letramento primário que estrutura o falasser.

Sobre a estrutura do falasser, engendra-se em um tempo lógico de elucubração de saber

agora que sou um homem; Assim seja quando eu envelhecer, Ou me deixe morrer! A Criança é pai do Homem; Eu poderia desejar que meus dias fossem; Vinculado a cada um por piedade natural." (WORDSWORTH, 2017, tradução nossa). que convoca o sujeito, frente ao real, a produzir respostas, um caminho que não é atravessado sem equívocos e tropeços. Dessa forma, considera-se que a passagem do letramento primário para o letramento secundário pode acarretar na produção de um "sintoma transitório" (LACAN, 1995, p. 292) para auxiliar a criança nesse processo de efetuação da estrutura e de entrada no discurso alfabético, pois "o discurso analítico pressupõe que o real do sexo produz impasses para os seres falantes" (CIRINO, 2001, p. 60).

Isso faz pensar que "existem angústias quase obrigatórias e que se resolvem, de certa maneira, por si mesmas" (SOLER, 2012c, p. 212). Nesse sentido, o sintoma disortográfico é despatologizado ao ser considerado uma resposta do sujeito frente a um impasse com o furo no saber, ou seja, com a não relação sexual, o que o faz assumir uma função primordial na estruturação da subjetividade, na medida em que serve como um anteparo à angústia da criança.

A investigação acerca do sintoma disortográfico de Lia, quando ela contava cinco anos, teve início com a elaboração de um enigma sobre o mal-estar que a angustiava: "por que só tem que ser dever de ler?" Com essa questão, ela começou a elucubração de saber acerca das letras de alíngua que, como cifras de gozo que constituem uma holófrase, ${ }^{3}$ escreviam o seu sintoma. Importante retomar o dito da menina carregado de letras e de cifras: "eu não consigo ler! Não leio xaxa, xela, xai, o h com a, e, i, o e u. Também não sei escrever o x."

Quando questionada sobre os significados de "xaxa", "xela" e "xai", disse literalmente: "são palavras que têm o x com as vogais". Diante disso, constata-se o equívoco de Lia ao não mencionar o aparecimento da letra "l" em "xela", pois, nessas três "palavras", as "vogais" não estavam acompanhadas somente do " $x$ ". Sendo assim, as palavras de Lia podem ser nomeadas como palavras do inconsciente-alíngua, pois

3 Segundo Lacan (2008), o termo holófrase diz respeito à solidificação da primeira dupla de significantes, não havendo o intervalo entre S1 e S2., unidade básica da língua. 
cada uma é um "significante sem significado, sem outro significado senão o enigma, sem significação que proteja da angústia" (SOLER, 2005, p. 111).

É importante ressaltar a homofonia entre "ler", atividade que a menina dizia não conseguir realizar, e o "lê", a pronúncia de Lia para a letra "l" que correspondia ao som da letra escutado, "lê", e não ao nome da letra, "éle" (FERREIRA, A., 2010, p. 453). Em outros momentos, tais letras, o "l" e o " $\mathrm{x}$ ", surgiram, novamente, em dois desenhos, criações frequentes nas sessões.

Figura 1 - "Letras no céu"

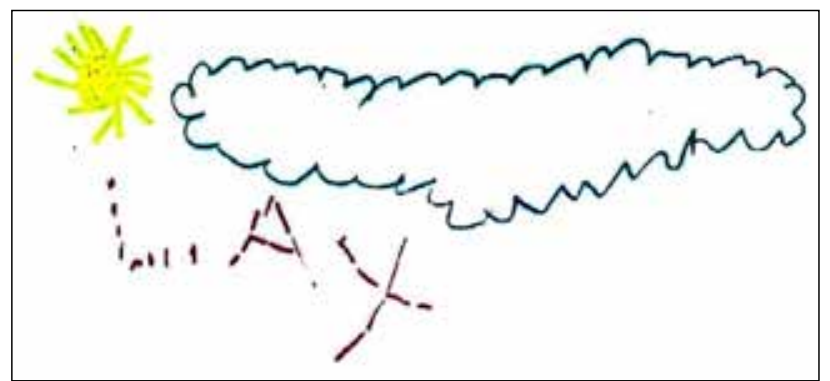

Fonte: Desenho produzido por Lia em uma sessão.

Sobre a primeira produção (Figura 1), Lia afirmou que eram "letras no céu" e as soletrou: "lê, a e xis", explicando: "eu risquei traços que, depois, eu vou unir com o lápis. Eu faço assim no dever." Nesse desenho, as letras " 1 " e " $x$ " aparecem tracejadas e em companhia da vogal “a”, mas não formam "palavras" como "xaxa", "xela" e "xai", conforme a fala da menina. Elas são letras soletradas sobre o papel.

Figura 2 - "Árvores na floresta"

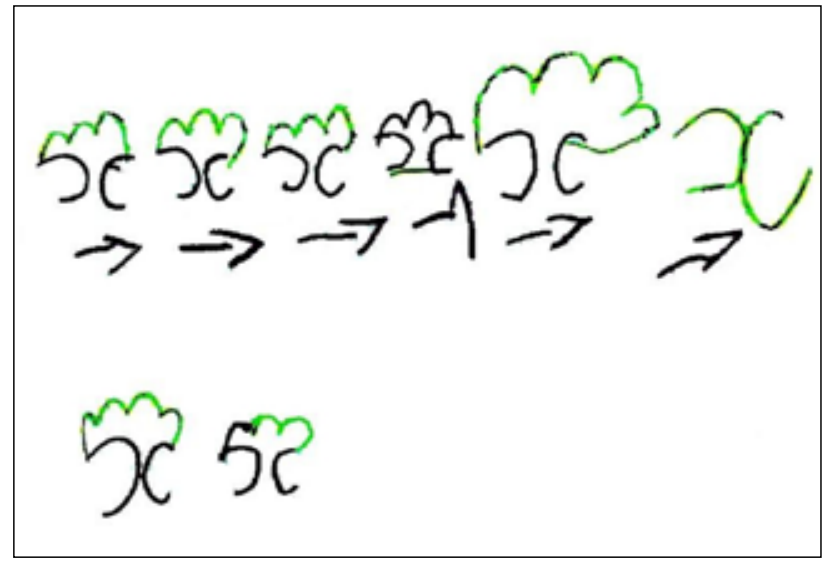

Fonte: Desenho produzido por Lia em uma sessão.
Na série de "árvores na floresta" produzida por Lia, no segundo desenho (Figura 2) pode ser notado o reaparecimento da letra " $x$ " representada através dos caules das árvores. Nesse desenho, 0 " $x$ " já foi escrito sem a necessidade de recorrer ao tracejado, porém emerge sob disfarce. Há, também, na primeira linha do desenho, setas que apontam para uma letra " $x$ " que se destaca no final da série ao não constituir o caule de uma árvore, um equívoco que retrata um enigma a ser elucubrado, o " $x$ " da questão de Lia. Na linha inferior, é possível observar, com maior nitidez, a representação do número " 5 ", a idade da menina quando produziu esses primeiros desenhos, um traço lido por mim, mas ainda não interpretado pela criança.

Ao compor palavras singulares, tracejar e grafar letras, Lia demonstra que está experienciando um momento lógico de passagem da escrita pictográfica, que remete ao letramento primário de alíngua, para o letramento secundário, que envolve a escrita com as letras do alfabeto. Assim, as letras rememoram o gozo cifrado da escrita de alíngua, que transborda no alfabeto ao fazer uso da equivocidade própria ao inconsciente e à literatura e à poesia.

Tanto na fala quanto na escrita, a letra rompe com a ortografia imposta pelo discurso pedagógico-universitário que rege a alfabetização para disortografar e produzir cifras que renunciam ao sentido e à compreensão imediata no nível da consciência. Desse modo, cada letra, cada fragmento de palavra só se deixa ler ao pé da letra, mediante um deciframento, uma elucubração hipotética acerca do saber do inconsciente-alíngua que se encontra holofraseado no dizer e que constitui o sintoma disortográfico (BORGES, 2010; DUNKER, 2011; SOLER, 2012a).

Os escritos de Lia manifestam as letras de alíngua que escrevem o sintoma disortográfico como cifras de gozo, holófrases, as quais, ao ultrapassarem o recalque e serem endereçadas à praticante da psicanálise, como uma carta en souffrance, demonstram os efeitos do trabalho de transferência em jogo no discurso 
do analista. Ao passo que é "responsável pela presença do inconsciente" (SOLER, 2012b, p. 34), o analista, sustentado em seu lugar de semblante de objeto $a$ pelo desejo do analista, é o "destinatário" (LACAN, 1998d, p. 848) da "carta/letra"4 (LACAN, 1998a, p. 26), a qual holofraseia o gozo e provoca angústia e sofrimento por ainda estar ilegível. Logo, o desejo do analista engendra a aposta de que o sintoma disortográfico escrito na carta/letra pode ser lido por meio da elucubração de saber sobre as letras de alíngua causada pelo desejo de saber.

A leitura da carta/letra é tributária da prática da letra, "um caminho ao avesso do momento inaugural do parlêtre: da prática do blábláblá à prática da letra" (FINGERMANN, 2012, p. 118), uma referência à homenagem feita à escritora Marguerite Duras por Lacan (2003a, p. 200) ao versar que "a prática da letra converge com o uso do inconsciente". Isso implica em dizer que o uso de gozo feito pelo inconsciente favorece a disortografia das letras de alíngua, já que o inconsciente-alíngua produz ajuntamentos de letras que veiculam a disjunção do real com o sentido e com a ordem (LACAN, 1985; SOLER, 2012a). Diante disso, a prática da letra, no discurso do analista, orienta-se para o real e desvela que a letra de alíngua que escreve o sintoma disortográfico pode ser lida ao pé da letra, na medida em que a letra $a$-borda e faz borda em torno do furo no saber que o real escreve.

Para tanto, o analista empreende a soletração do gozo cifrado e escrito no sintoma disortográfico a partir do corte no sentido realizado pela interpretação que visa o real (FINGERMANN, 2012). Assim, causado pelo desejo do analista, é feita a aposta de que o analisando, pela via do desejo de saber, possa bem-dizer e saber ler o sintoma para que produza uma resposta singular para o enigma que o sintoma circunscreve. Isso conduz a pensar que a questão produzida por Lia, "por que só tem que ser dever de ler?", versa sobre o enigma que se

4 Referência ao equívoco realizado por Lacan (1998a) a partir do duplo significado da palavra lettre em francês: carta e letra. encontra cifrado no sintoma disortográfico. Por isso, o "por que" de Lia não deve ser tomado como um testemunho de "uma avidez da razão das coisas" (LACAN, 2008, p. 209), por estar na chamada "idade da razão" (SOLER, 2014, p. 69, tradução nossa) e do aprendizado intelectual, e sim como uma pergunta que porta o enigma acerca do encontro do real ao experienciar a impossibilidade da relação sexual à medida que se depara com a falta no Outro $[\mathrm{S}(\not{A})]$, o que engendra a sua própria falta.

Sendo assim, 0 " $x$ " do enigma de Lia não diz respeito ao "dever de ler", mas ao "ler", verbo que equivoca com o "lê", a letra "l" emergida em "xela" e também tracejada no papel, um truque linguístico que faz uso da homofonia e corrobora que "o verbo é inconsciente - ou seja, mal-entendido" (LACAN, 1981, p. 12, tradução nossa). Nesse sentido, o "l", letra que permeava o nome próprio de Lia e de todos os seus familiares, é uma letra de alíngua que cifra o gozo e que escreve o sintoma disortográfico. Trata-se de um traço de gozo que é transmitido entre gerações vizinhas, entre pais e filhos, por meio da letra "l", e que, por isso, faz a relação sexual existir (LACAN, 2020b) pelo caminho da identificação.

Para adentrar na lógica da efetuação da estrutura, foi preciso que Lia se alienasse a esse dizer escrito com a letra de alíngua, como também, foi necessário interrogá-lo para dele se separar e se estruturar intérprete. Nesse trilhamento, Lia se deparou com impasses frente a esse saber inconsciente, e a resposta possível foi a produção do sintoma disortográfico: "eu não consigo ler!"

Na medida em que "o sintoma é uma frase" (MAGALHÃES, 2013, p. 91), ele consiste em um dito que porta o enigma do "lê" como um dizer a ser lido ao pé da letra. É nessa direção que o discurso do analista convoca o sujeito a "ler de outro modo" (LACAN, 2020b), o que implica em saber ler a falta no saber que aponta para o real da não relação sexual, apostando que da impotência diante da impossibilidade possa advir uma elucubração que engendre a criança como intérprete do saber inconsciente. É o que 
propõe Soler (2012c, p. 245) ao afirmar que o confronto com a não relação sexual deve ser um "starter" para que, do horror ao saber, a criança, como um "primeiro lógico" (MAGALHÃES, 2013, p. 211), dê partida a um trabalho de investigação e de invenção de soluções possíveis que levem em conta o real e que a conduzam ao desejo de saber.

Assim, diante da pergunta elaborada por Lia, "por que só tem que ser dever de ler?", a praticante da psicanálise se eximiu de enunciar uma resposta, que daria uma significação plena de sentido, para dar o starter, "você queria que fosse dever de quê?", o que abriu a possibilidade de a menina, em sua histoeria, descobrir-se intérprete ao construir respostas, teorias e ficções a fim de fazer borda ao real do enigma do sintoma disortográfico: "de pintar, mas só tem que ser de ler e de escrever."

\section{0 laço entre o saber inconsciente e o saber escolar: uma escrita para a despatologização do sintoma disortográfico}

A peça “O despertar da primavera”, de Frank Wedekind, foi objeto de discussão na Sociedade Psicanalítica de Viena, na qual Freud (1993, p. 101) declarou que "a obra tem grandes méritos e que ficará como um documento, que interessa à história da civilização e dos costumes". Segundo ele, Wedekind mostra ter uma compreensão profunda sobre a sexualidade humana, o que teria impulsionado o estudo das teorias sexuais pela psicanálise, o que aconteceu, anos depois, nos Três ensaios sobre a teoria da sexualidade (FREUD, 1972d). Nesse texto, Freud faz um paralelo entre as teorias sexuais infantis e o desejo de saber na criança, o que ressalta o enlace entre psicanálise, literatura e educação.

Freud (2006b, p. 183) concebe que a criança "é atraída, de maneira insuspeitadamente precoce e inesperadamente intensa, pelos problemas sexuais, e talvez seja até despertada por eles", o que o leva a afirmar que "nenhuma criança [...] pode evitar o interesse pelos problemas do sexo nos anos anteriores à puberdade" (FREUD, 2006e, p. 191). Sendo assim, "o interesse intelectual da criança pelos enigmas do sexo, o seu desejo de conhecimento sexual, revela-se numa idade surpreendentemente tenra" (FREUD, 2006c, p. 125), revestido pela curiosidade de descobrir o que os pais fazem para terem bebês. Tal curiosidade sexual, advinda das primeiras inquietações com os enigmas da origem e da diferença sexual, é o que desperta a pulsão de saber e a consequente fabricação das teorias sexuais, as quais são o prelúdio da estruturação do infantil que perdura na neurose e que participa da formação do sintoma (FREUD, 2006e; MAGALHÃES, 2013).

A relação da criança com o saber conduz Freud (2006g) a concluir que o esclarecimento sexual propicia não mais que a aquisição de um novo conhecimento, pois a criança não sacrifica o interesse pelas pesquisas e pelas teorizações para fazer uso do que lhe foi ensinado. Isso demonstra que, para a criança que está em um trabalho de engendrar-se intérprete, "o saber que importa é o saber custoso" (FERREIRA, T., 2000, p. 137), um saber singular produto da "criança-intérprete" (SOLER, 2012c, p. 245) que é elaborado em um tempo lógico de efetuação da estrutura ao ser mobilizado pelo desejo de saber. Portanto, o saber inconsciente não decorre da aprendizagem pedagógica, ainda que esteja atrelado à curiosidade intelectual e que impulsione o aprendizado do saber escolar.

Ao se confrontar com questões que versam sobre o enigma da vida, da morte e do sexo, os mistérios do corpo falante, a criança se dá conta da impotência do seu saber e passa a buscar desvelar a verdade a partir da suposição da existência de um saber todo dirigido ao Outro. Diante da constatação de que o Outro também vacila em seu saber, a criança se põe a produzir suas próprias teorias sexuais, que, embora "falsas" (FREUD, 2006e, p. 195), portam um "fragmento da verdade" (FREUD, 2006e, p. 195), o que se 
mostra presente no enunciado de Lacan (1992, p. 175) de que "a verdade é trabalho de criança, ou seja, um parto". Embora o exercício de produção de teorias e de mitos fracasse ao pretender alcançar a verdade toda, ele é pulsional e não cessa de manter o sujeito em posição de desejar saber ao bordejar o furo no saber escrito pelo real, o que engendra a escrita de uma ficção para tentar dizer o impossível de dizer.

Com isso, as teorias sexuais da criança se constituem como uma elucubração de saber sobre alíngua, um trabalho de interpretação que busca dar conta da impossibilidade da relação sexual, à medida que "o impasse sexual secreta as ficções que racionalizam a impossibilidade da qual provém" (LACAN, 2003c, p. 531). Assim, o furo da não relação sexual que marca a incompletude do saber lança a criança ao encontro da verdade não toda e a precipita ao desejo de saber.

Nessa perspectiva, Lia falou nas sessões sobre o fato de sua mãe estar grávida de gêmeos e seu desejo de saber sobre o sexo dos bebês. Após compartilhar a revelação de que os dois irmãos seriam meninos, Lia contou uma brincadeira que teve com uma amiga: "a gente estava brincando de pai e filho, e minha amiga achou um boneco, ele tinha um pinto, era um homem. Ela achou que era uma menina, mas não era, não tinha o xerecão de menina!" Lia também produziu suas teorias sexuais a partir do desenho de uma "pipa" (Figura 3), afirmando que "tem pipa de homem e pipa de mulher".

Figura 3 - "Pipa de homem e pipa de mulher"

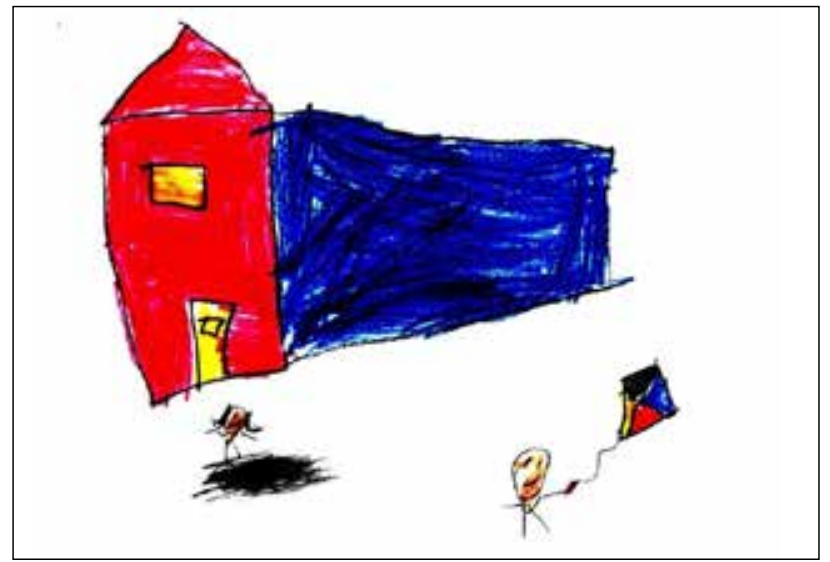

Fonte: Desenho produzido por Lia em uma sessão.
A partir disso, produziu novas articulações: "homem tem pipa, carrinho e leão, e mulher tem borboleta, boneca e flor", construções, em associação livre, que revelaram seu momento lógico de elucubração do saber inconsciente que versa sobre a diferença entre os sexos. Mais adiante, o significante "pipa" retornou em seu dito: "desenhei outra pipa". Ao falar a palavra "pipa", Lia descobriu com surpresa: "pipa tem as mesmas letras de papai, é só trocar de lugar!". É importante sublinhar que Lia, no início dos atendimentos, ao relatar que não lia, trouxe a dificuldade com a letra " $x$ " presente em "хаха" e "xela", que retorna, posteriormente, em "xerecão". Também se perguntou, nas primeiras sessões, por que não podia ser desenho de pintar, e, assim, também a letra "p" retornou, promovendo a histoerização em análise como elucubração acerca das letras do inconsciente-alíngua.

Essas letras do inconsciente-alíngua não reenviam a um novo sentido, mas para o saber-fazer com o inconsciente-alíngua. Isso pode ser aproximado ao que Freud (2006d) elabora sobre as brincadeiras e os jogos serem a ocupação favorita e mais intensa da criança e aproxima o brincar à criação poética, pois a criança e o poeta criam um mundo próprio repleto de fantasia para transformarem o que há de doloroso no real em algo prazeroso. Com isso, ele parece vincular a presença da repetição nas brincadeiras e desenhos infantis à função de elaborar o encontro do real: "é claro que em suas brincadeiras as crianças repetem tudo que lhes causou uma grande impressão na vida real, e assim procedendo, ab-reagem a intensidade da impressão, tornando-se, por assim dizer, senhoras da situação" (FREUD, 2006f, p. 27).

Dessa forma, o que importa não é a produção em si, "encadeamento dos jogos, os comportamentos e, especialmente, os desenhos" (SOLER, 1991, p. 105), mas a insistência com que o conteúdo retorna e as mudanças que nele ocorrem (MAGALHÃES, 2013). Nesse sentido, cada manifestação da criança é um dito que 
porta um dizer que se revela em letras e significantes que escapam para serem pinçados pelo analista.

A partir da construção de Soler (2012a) de que o sintoma do sujeito é disortográfico, o que a interlocução entre psicanálise, literatura e poesia, desde Freud e com Lacan, já esboçava, elabora-se que o impasse da criança com o saber em um momento lógico de efetuação da estrutura e de entrada no discurso alfabético pode ser lido pela psicanálise como um sintoma disortográfico. Essa análise sustenta que as dificuldades decorrentes da aprendizagem da leitura e da escrita durante a alfabetização, muitas vezes, interpretadas e diagnosticadas como déficits e como transtornos, representam manifestações do inconsciente-alíngua que apontam para a participação da subjetividade da criança em seu letramento secundário (DUNKER, 2011). Sendo assim, o saber inconsciente e o saber escolar se enlaçam, revelando a suplementaridade entre ambos no que diz respeito à efetuação da estrutura da criança na passagem de objeto interpretado a sujeito intérprete.

\section{Apontamentos Finais}

O sintoma da criança, muitas vezes, é a via pela qual ela passa de interpretada a intérprete. Isso tem relação com a definição de Lacan (2003d) de sintoma como um acontecimento de corpo tal qual uma cantilena, uma lalação representada como a água da linguagem que banha o infans e que deixa marcas do gozo do Outro. A lalação entoada como "l'on l'a, l'on l'a de l'air, l'on l'aire, de l'on l'a", em francês, joga com a fonética jocosa, que pode ser cantarolada como "a gente o tem, a gente tem ares de, a gente areja a partir do, a gente tem" (LACAN, 2003d, p. 565).

O cantarolar da lalação, ao tratar o sintoma como um acontecimento de corpo, faz alusão à afirmação de Freud (1972g) de que a psicanálise foi obrigada a atribuir a origem da vida mental dos adultos à vida das crianças, o que está diretamente relacionado ao que foi de- senvolvido até aqui sobre a alíngua. A alíngua conecta o gozo do Um, do significante Um fora sentido, que é condição para que a criança, sensível aos efeitos pulsionais de alíngua, adentre na linguagem que, com Lacan, é definida como uma elucubração de saber acerca de alíngua.

Desse modo, a possibilidade de a criança manejar as letras do alfabeto para criar uma língua singular é tributária da sua estruturação como sujeito intérprete e leitor das letras de alíngua que já estavam escritas no texto do seu romance como um letramento primário, porém holofraseadas e ainda ilegíveis, visto que "o sujeito só inventa o significante a partir de alguma coisa que já está lá para ser lida" (KAUFMANN, 1996, p. 473). No entanto, a realização dessa leitura necessita de tempo, um tempo lógico de elucubração de saber sobre alíngua, a qual, como no caso de Lia, demandou, transitoriamente, a produção do sintoma disortográfico como recurso para que viesse a desembaraçarse dos impasses com o saber.

Por meio da histoeria da menina com as letras, foi possível verificar o enlace entre as letras do alfabeto e as letras de alíngua, na medida em que a letra que é caligrafada sobre o papel se revela como suporte para a manifestação do saber inconsciente. Isso atesta que não somente o sintoma do sujeito é disortográfico, bem como o inconsciente do falasser, pois este é escrito e escreve segundo uma lógica disortográfica que é sujeita à equivocidade.

O embaraço com a leitura do "lê", letra de gozo de alíngua, que, pela via do equívoco, fez a menina ter um impasse com o ato de "ler", realça que Lia percorria um momento lógico de efetuação da estrutura e de elucubração de saber sobre os enigmas da vida, do sexo e da morte. Tal constatação é uma das contribuições que a psicanálise tem a oferecer aos campos discursivos que também se debruçam sobre as questões que envolvem a criança e o saber, visto que sustenta que o aprendizado das letras do saber ortográfico está enlaçado à elucubração das letras do saber disortográfico do inconsciente-alíngua. 
Foi, num tempo singular, permeado por enigmas e por impasses com o escrever, com o ler e com o "lê", com o "x" e com o "h", que Lia pôde dizer: "eu aprendi o alfabeto e juntei as letras." Fez, então, ajuntamentos e conseguiu ler, escrever e se engendrar intérprete das letras de alíngua e das letras do alfabeto. Lia também elaborou: "vi que é importante ler, aprendo muita coisa lendo. A pró mandava muito dever difícil, agora, é fácil." Aqui, diante do reaparecimento do significante "difícil", o qual era recorrente enquanto a dificuldade com as letras se presentificava, foi questionada sobre o que era o "dever difícil" e que, agora, tornara-se "fácil", afirmando: "dever difícil é o dever que não vem com a resposta."

Isso atesta a pertinência da aposta na causalidade psíquica em detrimento de considerar a entrada na leitura e na escrita como somente uma aquisição de habilidades cognitivas pela via de um adestramento escolar. A literatura e a poesia, como exposto, fazem um uso da linguagem no qual exploram os truques linguísticos e, assim, adiantam-se no tratamento da questão de que todo sintoma é em si disortográfico, o que contribui para a despatologização da dificuldade de aprendizagem da criança. É preciso, portanto, escutar e ler a singularidade nos impasses com o saber, uma recomendação que cabe aos educadores e aos profissionais da saúde e que pode conduzir à redução ou à eliminação dos diagnósticos apressados que propagam a patologização e a medicalização do sintoma disortográfico.

\section{REFERÊNCIAS}

BAUTHENEY, K. C. S. F. Transtornos de aprendizagem: quando "ir mal na escola" torna-se um problema médico e/ou psicológico. 2011. 279 f. Tese (Doutorado m Educação) - Faculdade de Educação, Universidade de São Paulo (USP), São Paulo, 2011. Disponível em: https://www.teses.usp. br/teses/disponiveis/48/48134/tde-13122011124145/publico/KATIA_CRISTINA_SILVA_FORLI_ BAUTHENEY.pdf. Acesso em: 03 set. 2015.

BORGES, S. Psicanálise, linguística, linguisteria.
São Paulo: Escuta, 2010.

CIRINO, O. Psicanálise e Psiquiatria com crianças: desenvolvimento ou estrutura. Belo Horizonte: Autêntica, 2001.

COUTO, M. P. do. Da queixa escolar à demanda de análise: uma mudança de posição subjetiva diante do saber e da verdade. In: GUERRA, A. M. C.; LIMA, N. L. de (org.). A clínica de crianças com transtornos no desenvolvimento: uma contribuição no campo da Psicanálise e da Saúde Mental. Belo Horizonte: Autêntica/FUMEC, 2003. p. 149-167.

CUNHA, C. F. da; CINTRA, L. Nova gramática do português contemporâneo. 4. ed. Rio de Janeiro: Lexikon, 2007.

DUNKER, C. I. L. Transitivismo e letramento: constituição do sujeito e entrada no discurso. 2011. Disponível em: https://www5.pucsp.br/ linguagemesubjetividade/PDF/biblioteca_virtual. pdf. Acesso em: 10 mar. 2015.

EDINGTON, V. L. T. A medicalização da infância: uma leitura psicanalítica. 2012. 98 f. Dissertação (Mestrado em Psicologia) - Instituto de Psicologia, Universidade Federal da Bahia (UFBA), Salvador, 2012.

FERNANDES, A. H. Psicanálise: interpretação? In: FERNANDES, A. H. (org.). A lógica da interpretação. Salvador: Associação Científica Campo Psicanalítico, 2012. p. 52-61.

FERNANDES, A. H. A psicanálise diante do DSM e do capitalismo. In: PEREIRA, M. de F. A. (org.). Real, simbólico, imaginário e sintoma na clínica psicanalítica. Salvador: Associação Científica Campo Psicanalítico, 2013. p. 221-228.

FERNÁNDEZ, A. Y. Et al. Avaliação e intervenção da disortografia baseada na semiologia dos erros: revisão da literatura. Revista CEFAC, v. 12, n. 3, p. 499-504, 2010. Disponível em: http://www.scielo. br/pdf/rcefac/v12n3/196-09. Acesso em: 03 set. 2015.

FERREIRA, T. A escrita da clínica: psicanálise com crianças. Belo Horizonte: Autêntica, 2000.

FERREIRA, T. As novas nomeações do adoecimento psíquico das crianças e adolescentes na contemporaneidade e o cuidado no tratamento (distúrbios alimentares, hiperatividade, toxicomanias e depressão infantil). In: JORNADA ESTADUAL DE SAÚDE MENTAL DA CRIANÇA E DO ADOLESCENTE, 1., 2008, Betim, MG. Anais [...]. Betim, MG: CERSAMI, 2008. 
FERREIRA, A. B. de H. Mini Aurélio: o dicionário da língua portuguesa. 8. ed. rev. atual. Curitiba: Positivo, 2010.

FINGERMANN, D. Da lógica da interpretação à prática da letra. Stylus, Rio de Janeiro, n. 24, p. 117-124, 2012.

FREUD, S. A interpretação dos Sonhos. In: FREUD, S. Edição Standard Brasileira das Obras Psicológicas Completas de Sigmund Freud, vol. IV e V. Rio de Janeiro: Imago, 1972a.

FREUD, S. Os meios de representação dos sonhos. In: FREU.D, S Edição Standard Brasileira das Obras Psicológicas Completas de Sigmund Freud, vol. IV. Rio de Janeiro: Imago, 1972b. p. 330-360.

FREUD, S. 0 esquecimento de nomes próprios. In: FREUD, S. Edição Standard Brasileira das Obras Psicológicas Completas de Sigmund Freud, vol. VI. Rio de Janeiro: Imago, 1972c. p. 263-288.

FREUD, S. Três ensaios sobre a teoria da sexualidade. In: FREUD, S. Edição Standard Brasileira das Obras Psicológicas Completas de Sigmund Freud, vol. VIII. Rio de Janeiro: Imago, 1972d. p. 129-252.

FREUD, S. Escritores criativos e devaneio. In: FREUD, S. Edição Standard Brasileira das Obras Psicológicas Completas de Sigmund Freud, vol. IX. Rio de Janeiro: Imago, 1972e. p. 149-158.

FREUD, S. Recomendações aos médicos que exercem a psicanálise. In: FREUD, S. Edição Standard Brasileira das Obras Psicológicas Completas de Sigmund Freud, vol. XII. Rio de Janeiro: Imago, 1972f. p. 146-159.

FREUD, S. 0 interesse científico da psicanálise. In: FREUD, S. Edição Standard das Obras Brasileiras de Sigmund Freud, vol. XIII. Rio de Janeiro: Imago, 1972g. p. 199-226.

FREUD, S. Intervention de Freud sur L'Éveil du Printemps à la Société psychologique du mercredi à Vienne, en 1907. In: WEDEKIND, F. L'éveil du printemps. Paris: Gallimard, 1993. p. 99-107.

FREUD, S. A interpretação dos sonhos (Primeira parte). In: FREUD, S. Obras psicológicas completas de Sigmund Freud: edição standard brasileira, vol. IV. Rio de Janeiro: Imago, 2006a. p. 13-363.

FREUD, S. Três ensaios sobre a teoria da sexualidade. In: FREUD, S. Obras psicológicas completas de Sigmund Freud: edição standard brasileira, vol. VII. Rio de Janeiro: Imago, 2006b. p. 117-231.
FREUD, S. 0 esclarecimento sexual das crianças (Carta aberta ao Dr. M. Fürst). In: FREUD, S. Obras psicológicas completas de Sigmund Freud: edição standard brasileira, vol. IX. Rio de Janeiro: Imago, 2006c. p. 119-129.

FREUD, S. Escritores criativos e devaneio. In: FREUD, S. Obras psicológicas completas de Sigmund Freud: edição standard brasileira, vol. IX. Rio de Janeiro: Imago, 2006d. p. 131-143.

FREUD, S. Sobre as teorias sexuais das crianças. In: FREUD, S. Obras psicológicas completas de Sigmund Freud: edição standard brasileira, vol. IX. Rio de Janeiro: Imago, 2006e. p. 187-204.

FREUD, S. Além do princípio de prazer. In: FREUD, S. Obras psicológicas completas de Sigmund Freud: edição standard brasileira, vol. XVIII. Rio de Janeiro: Imago, 2006, 2006f. p. 11-75.

FREUD, S. Análise terminável e interminável. In: FREUD, S. Obras psicológicas completas de Sigmund Freud: edição standard brasileira, vol. XXIII. Rio de Janeiro: Imago, 2006g. p. 223-270.

KAUFMANN, P. Dicionário enciclopédico de psicanálise: o legado de Freud e Lacan. Rio de Janeiro: Zahar, 1996.

LACAN, J. O seminário sobre "A carta roubada”. In: LACAN, J. Escritos. Rio de Janeiro: Zahar, 1998a. p. 13-45.

LACAN, J. A psicanálise e seu ensino. In: LACAN, J. Escritos. Rio de Janeiro: Zahar, 1998b. p. 438-460.

LACAN, J. De uma questão preliminar a todo tratamento possível da psicose. In: LACAN, J. Escritos. Rio de Janeiro: Zahar, 1998c. p. 537-590.

LACAN, J. Posição do inconsciente. In: LACAN, J. Escritos. Rio de Janeiro: Zahar, 1998d. p. 843-864.

LACAN, J. 0 Seminário, livro 4: a relação do objeto. Rio de Janeiro: Zahar, 1995.

LACAN, J. O Seminário, livro 5: as formações do inconsciente. Rio de Janeiro: Zahar, 1999.

LACAN, J. O Seminário, livro 11: os quatro conceitos fundamentais da Psicanálise. Rio de Janeiro: Zahar, 2008.

LACAN, J. Homenagem a Marguerite Duras pelo arrebatamento de Lol V. Stein. In: LACAN, J. Outros Escritos. Rio de Janeiro: Zahar, 2003a. p. 198-205.

LACAN, J. Lituraterra. In: LACAN, J. Outros Escritos. Rio de Janeiro: Zahar, 2003b. p. 15-25.

LACAN, J. Televisão. In: LACAN, J. Outros Escritos. 
Rio de Janeiro: Zahar, 2003c. p. 508-543.

LACAN, J. Joyce, o sintoma. In: LACAN, J. Outros Escritos. Rio de Janeiro: Zahar, 2003d. p. 560-566.

LACAN, J. Prefácio à edição inglesa do Seminário 11. In: LACAN, J. Outros Escritos. Rio de Janeiro: Zahar, 2003e. p. 567-569.

LACAN, J. o Seminário, livro 17: o avesso da psicanálise. Rio de Janeiro: Zahar, 1992.

LACAN, J. O Seminário, livro 20: mais, ainda. Rio de Janeiro: Zahar, 1985.

LACAN, J. o Seminário, livro 23: o sinthoma. Rio de Janeiro: Zahar, 2007.

LACAN, J. Le Seminaire, livre 22: R.S.I. 1974-1975. Disponível em: http://staferla.free.fr/S22/S22\%20 R.S.I.pdf. Acesso em: 22 dez. 2020a.

LACAN, J. Le Séminaire, livre 25: le moment de conclure. 1977-1978. Disponível em: http:// staferla.free.fr/S25/S25.pdf. Acesso em: 22 dez. 2020b.

LACAN, J. Le malentendu. Ornicar, Paris, n. 22/23, p. 11-14, 1981.

LIMA, T. C. F. de; PESSOA, A. C. R. G. Dificuldade de aprendizagem: principais abordagens terapêuticas discutidas em artigos publicados nas principais revistas indexadas no LILACS de fonoaudiologia no período de 2001 a 2005. Revista CEFAC, São Paulo, v. 9, n. 4, p. 469-476, 2007. Disponível em: http:// www.scielo.br/pdf/rcefac/v9n4/04.pdf. Acesso em: 06 abr. 2016.

MAGALHÃES, S. C. A criança em nós. Salvador: Associação Científica Campo Psicanalítico: Ágalma, 2013.

MELO, R. Uma interpretação para a medicalização da infância e da adolescência. In: PACHECO, A. L. P.; OLIVEIRA, B. (org.). Criança: objeto ou sujeito. 15 anos da Rede de Psicanálise e Infância do FCL-SP. São Paulo: Escuta/Fórum do Campo Lacaniano, 2016. p. 249-266.

MUÑOZ, J. Et al. Descrição, avaliação e tratamento dos transtornos da aprendizagem. In: CABALLO, V.; SIMÓN, M. Manual de psicologia clínica infantil e do adolescente. São Paulo: Livraria Santos, 2015.

NOMINÉ, B. A criança e o saber. Marraio, Rio de Janeiro, n. 3, p. 57-67, 2002.

PACHECO, A. L. P. Da fantasia de infância ao infantil na fantasia: a direção do tratamento na psicanálise com crianças. São Paulo: Annablume, 2012.
RESTREPO, B. E. M. O sujeito do inconsciente não se educa. In: FOGUEL, E. (org.). Amor, desejo e gozo. Salvador: Campo Psicanalítico, 2014. p. 391-410.

SALDANHA, C. M. T. 0 sintoma disortográfico da criança em impasse com o saber: uma construção de caso clínico em psicanálise. 2017. 116 f. il. color. Dissertação (Mestrado em Psicologia) - Instituto de Psicologia, Universidade Federal da Bahia (UFBA), Salvador, 2017.

SAMPAIO, S. Aspectos neuropsicopedagógicos da dislexia e sua influência em sala de aula. In: SAMPAIO, S.; FREITAS, I. B. de. Transtornos e dificuldades de aprendizagem: entendendo melhor os alunos com necessidades educativas especiais. Rio de Janeiro: Wak, 2011. p. 17-36.

SAURET, M. J. 0 infantil e a estrutura. São Paulo: Escola Brasileira de Psicanálise - São Paulo, 1998.

SOLER, C. Uma dificuldade da psicanálise de criança. In: SOLER, C. Artigos clínicos: transferência, interpretação, psicose. Salvador: Fator, 1991. p. 104-107.

SOLER, C. 0 que Lacan dizia das mulheres. Rio de Janeiro: Zahar, 2005.

SOLER, C. Lacan, o inconsciente reinventado. Rio de Janeiro: Cia de Freud, 2012a.

SOLER, C. 0 inconsciente: que é isso? São Paulo: Annablume, 2012b.

SOLER, C. Declinações da angústia. São Paulo: Escuta, 2012c.

SOLER, C. Lo que queda de la infancia. Medellín: Asociación Foro del Campo Lacaniano de Medellín, 2014.

ORGANIZAÇÃO DAS NAÇÕES UNIDAS PARA A EDUCAÇÃO, A CIÊNCIA E A CULTURA (UNESCO). Relatório de monitoramento global de educação para todos. Paris: UNESCO, 2014. Disponível em: https://unesdoc.unesco.org/ark:/48223/ pf0000225654_por. Acesso em: 10 mar. 2015.

ORGANIZAÇÃO DAS NAÇÕES UNIDAS PARA A EDUCAÇÃO, A CIÊNCIA E A CULTURA (UNESCO). Relatório de monitoramento global da educação. Paris: UNESCO, 2016. Disponível em: https:// unesdoc.unesco.org/ark:/48223/pf0000245745_ por. Acesso em: 10 mar. 2015.

VALERIANO, R. Disortografia: distúrbio ou falta de oportunidade? In: SAMPAIO, S.; FREITAS, I. B. de. Transtornos e dificuldades de aprendizagem: entendendo melhor os alunos com necessidades 
educativas especiais. Rio de Janeiro: Wak, 2011. 12 ago. 2020.

p. 83-104.

WORDSWORTH, W. The rainbow. The Rea-

der, Liverpool, 20 fev. 2017. Disponível em:

https://www.thereader.org.uk/featured-poem-

the-rainbow-by-william-wordsworth/. Acesso em:
ZWEIG, S.; FREUD, S. Correspondance. Paris: Rivages, 1991.

Recebido em: $15 / 08 / 2020$

Aprovado em: 06/12/2020

Este é um artigo publicado em acesso aberto sob uma licença Creative Commons. 